\title{
Acute effect of a supplemented milk drink on bone metabolism in healthy postmenopausal women is influenced by the metabolic syndrome
}

\author{
Sunethra D. C. Thomas ${ }^{1,2^{*}}$, Howard A. Morris ${ }^{3,4}$ and B. E. C. Nordin ${ }^{2 \wedge}$
}

\begin{abstract}
Background: Dietary factors acutely influence the rate of bone resorption, as demonstrated by changes in serum bone resorption markers. Dietary calcium exerts its effect by reducing parathyroid hormone levels while other components induce gut incretin hormones both of which reduce bone resorption markers. The impact of dietary calcium on bone turnover when energy metabolism is modulated such as in metabolic syndrome has not been explored. This study was designed investigate whether metabolic syndrome or a greater amount of visceral fat influences the impact of dietary calcium on bone turnover.

Methods: The influence of the metabolic syndrome on effects of dietary calcium on bone turnover in community dwelling postmenopausal women was studied. Twenty five volunteers consumed $200 \mathrm{~mL}$ of low fat milk with additional $560 \mathrm{mg}$ calcium (one serve of $\mathrm{Milo}^{\oplus}$ ) in the evening on one occasion. Fasting morning serum biochemistry before and after the milk drink with lumber spine bone density, bone mineral content, fat and lean mass using dual energy X-ray absorptiometry (DXA) and waist circumference were measured. The women were divided into 2 groups using the waist measurement of $88 \mathrm{~cm}$, as a criterion of metabolic syndrome. Student's $\mathrm{t}$ tests were used to determine significant differences between the 2 groups.

Results: The lumbar spine mineral content was higher in women with metabolic syndrome. After consuming the milk drink, serum bone resorption marker $C$ terminal telopeptide (CTX) was suppressed to a significant extent in women with metabolic syndrome compared to those without.

Conclusions: The results suggests that dietary calcium may exert a greater suppression of bone resorption in post-menopausal women with metabolic syndrome than healthy women. Despite substantial evidence for close links between energy metabolism and bone metabolism this is the first report suggesting visceral fat or metabolic syndrome may influence the effects of dietary calcium on bone metabolism.
\end{abstract}

Keywords: Dietary calcium, Postmenopausal, Metabolic syndrome, Osteoporosis

\section{Introduction}

Osteoporosis is common in postmenopausal women, in which estrogen deficiency plays an important role. Low dietary calcium intake and vitamin D deficiency also contribute to the high prevalence of osteoporosis amongst these women. Post-menopausal bone loss is driven by

\footnotetext{
* Correspondence: Devika.thomas@health.sa.gov.au

Deceased

'Department of Medicine, University of Adelaide, Adelaide, South Australia, Australia

2Endocrine and Metabolic Unit, Royal Adelaide Hospital, Level 7, Royal Adelaide Hospital, North Terrace, Adelaide, South Australia 5000, Australia

Full list of author information is available at the end of the article
}

increased rate of bone resorption relative to bone formation which is demonstrated biochemically by an increase in serum levels of metabolites of type I collagen.

Dietary calcium and vitamin D are essential for skeletal health throughout life and are recognised as bone sparing nutrients $[1,2]$. The calcium requirement rises after the menopause due to increased losses and reduced intestinal absorption [3, 4].

The main dietary source of calcium is dairy food with high calcium bioavailability and optimal ratio of calcium to phosphate optimal for intestinal absorption [5].

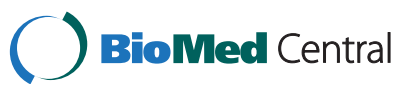

(c) 2015 Thomas et al. Open Access This article is distributed under the terms of the Creative Commons Attribution 4.0 International License (http://creativecommons.org/licenses/by/4.0/), which permits unrestricted use, distribution, and reproduction in any medium, provided you give appropriate credit to the original author(s) and the source, provide a link to the Creative Commons license, and indicate if changes were made. The Creative Commons Public Domain Dedication waiver (http://creativecommons.org/publicdomain/zero/1.0/) applies to the data made available in this article, unless otherwise stated. 
Regular intake of vitamin D-fortified, calcium rich food, such as dairy inhibits markers of bone resorption in postmenopausal women -within 4 to 8 weeks [6-8]. An inadequate dietary calcium intake in post-menopausal women leads to increased risk of osteoporosis and fragility fractures [9]. However a longitudinal prospective cohort study did not show a reduction in fracture risk or osteoporosis rates with an increased dietary calcium intake [10].

The variable results in terms of bone mineral density and fracture reduction may arise from factors other than dietary calcium and vitamin $\mathrm{D}$ influencing bone metabolism. Among these factors, energy nutrients as well as dysregulation of metabolic pathways as occurs in metabolic syndrome may be important factors.

To our knowledge, the acute effects of dietary calcium on bone metabolism in the context of metabolic syndrome in postmenopausal women have not been evaluated. The present study determined the interaction between a single evening supplemented milk drink and anthropormetric and biochemical measures of metabolic syndrome on bone resorption in post-menopausal women. The aim is to investigate if metabolic syndrome or a greater amount of visceral fat influences the impact of dietary calcium on bone resorption in post-menopausal women.

\section{Method}

\section{Participant recruitment}

Ethics approval as granted by the Royal Adelaide Human Research Ethics Committee (Protocol number 09071; 29th July 2009). Community dwelling postmenopausal women who participated in a non interventional observational study were invited to participate in the current study. They completed a general health, a dietary calcium intake questionnaire and a consent form. Subjects who were taking calcium supplements were instructed to cease the supplements for 7 days prior to participation.

\section{Intervention}

On the day of the study each subject had morning fasting blood samples collected for routine electrolytes, liver function, creatinine, urea, total cholesterol, glucose, calcium, phosphate (analysed by Olympus AU 5700, Olympus Japan), parathyroid hormone (PTH,-Immulite 2000, Siemens Healthcare Australia), 25OH vitamin D (25OHD) (IDS-iSYS, Immunodiagnostic Systems, -UK) and Cterminal telopeptide of type I collagen (CTX,-Roche E170, Roche Diagnostics, Australia). Subjects were provided with Pura Tone milk (Pura, Victoria, Australia) $(1 \mathrm{~L})$ and a sachet of Milo (Nestle, Australia) (20 g) with a $200 \mathrm{~mL}$ plastic measuring cup. They were instructed to measure out $200 \mathrm{~mL}$ milk (containing $400 \mathrm{mg} \mathrm{Ca}, 10 \mathrm{~g}$ protein, $13.5 \mathrm{~g}$ carbohydrate) and add the sachet of Milo (containing $160 \mathrm{mg} \mathrm{Ca}, 2.6 \mathrm{~g}$ protein, $13.3 \mathrm{~g}$ carbohydrate). The drink (containing a total of $560 \mathrm{mg} \mathrm{Ca}$ ) either warm or cold, was taken at $9 \mathrm{pm}$ the same night as the blood test. The next morning another set of fasting blood samples were collected from each subject to repeat the assays of the biochemical variables, except for 25OHD. All subjects had a radiocalcium absorption study performed using ${ }^{45} \mathrm{Ca}$ [11]) within 12 months of the study and a DXA bone mineral density measurement (Norland XR 36, Swissray International Switzerland) within 6 months of the study. An abdominal fat and lean mass obtained from the lumbar spine DXA, height, weight and waist circumference (WC) were recorded. Subjects-completed a validated food frequency questionnaire to ascertain their habitual dietary calcium intake.

Subjects were divided into 2 groups according to their WC using $88 \mathrm{~cm}$ as a cut off with $\mathrm{WC}>88 \mathrm{~cm}$ indicating metabolic syndrome (ATP III criteria) [12]. WC was chosen to categorise subjects into metabolic syndrome because it compares closely with the BMI and visceral fat. Waist circumference is also the theme of a public education campaign conducted by the Heart Foundation of Australia [13]. The Heart Foundation recommends measuring the waist circumference as an inexpensive and non-invasive method to indicate visceral fat and a predictor of risk for chronic disease such as diabetes and heart disease.

\section{Statistical analysis}

A Student's $t$ test was performed to determine significant difference between measured variables before and after the supplemented milk drink, and also differences between the metabolic syndrome women and lean women. Linear regression analysis and a correlation matrix were used to determine correlations between variables.

\section{Results}

Twenty five postmenopausal women volunteered to participate in the study. Demographic data and anthropometric measurements are given in Table 1.

Their mean fractional calcium absorption was 0.67 (range 0.33 to 1.24; normal $>0.5$ ) and mean urine calcium/ creatinine ratio was 0.28 (range 0.03 to 0.73 ; reference interval 0.03-0.4). There was no significant difference in

Table 1 Demographic and anthropometric data for all subjects

\begin{tabular}{llll}
\hline Variable & Mean & SD & Range \\
\hline Age (years) & 63 & 5 & $51-71$ \\
Years since menopause & 12 & 7 & $1-28$ \\
Height $(\mathrm{m})$ & 1.62 & 0.05 & $1.55-1.71$ \\
Weight $(\mathrm{kg})$ & 66 & 9 & $50-81$ \\
Waist circumference $(\mathrm{cm})$ & 84 & 9 & $67-99$ \\
BMI (kg/m2) & 24.9 & 3 & $20-31$ \\
Habitual daily Ca intake (dietary; $\mathrm{mg})$ & 1012 & 260 & $642-1605$ \\
\hline
\end{tabular}


the fractional calcium absorption, urinary calcium excretion or habitual daily calcium intake between the women with and without metabolic syndrome, as defined by a $\mathrm{WC}>88 \mathrm{~cm}$.

Serum CTX levels, a marker of bone resorption, was negatively related to abdominal fat mass (Fig. 1) and serum 25OHD was negatively related to WC $(P<0.01)$ amongst all the subjects at baseline. Biochemical variables before and after the supplemented milk drink for all women are presented in Table 2. Only ionised calcium changed significantly after the supplemented milk.

WC, fasting blood glucose and lipid profiles were available as determinants of metabolic syndrome in these women. Fasting blood glucose of $>5.6 \mathrm{mmol} / \mathrm{L}$, triglyceride $>1.7 \mathrm{mmol} / \mathrm{L}$ and $\mathrm{HDL}<1.29 \mathrm{mmol} / \mathrm{L}$ (as suggested by the American Heart Foundation) [14] were not used because these biochemical criteria did not distinguish between the 2 groups. In support of the use of WC as a marker of metabolic syndrome the change in blood glucose after the supplemented milk drink correlated with WC, abdominal fat mass and body weight $(P<0.01)$.

Table 3 represents the anthropomorphic measures on the two groups based on WC $(<88 \mathrm{~cm}$ compared with $>$ $88 \mathrm{~cm}$ ). There was no significant difference in the fractional calcium absorption, urinary calcium excretion or habitual daily calcium intake between them. Lumbar spine bone mineral content was increased and bone mineral density tended to be higher in those with a greater WC $(\geq 88 \mathrm{~cm})$. These women also had a significantly greater abdominal fat mass, body weight and BMI than those with $\mathrm{WC}<88 \mathrm{~cm}$. There was no significant difference in height or lean mass between the groups. Table 3 also presents the measured biochemical variables in women with $\mathrm{WC}<88 \mathrm{~cm}$ and with $\mathrm{WC} \geq 88 \mathrm{~cm}$.

The changes in measured biochemical variables after the supplemented milk drink in women with and without metabolic syndrome are presented in Table 4. The changes in bone turnover markers ALP and CTX and the calciotropic hormone PTH in each group after the milk drink are depicted in Fig. 2. Women with a larger WC responded to the supplemented milk drink with a significant fall in CTX levels with the fall in ALP tending to significance. There is no evidence that these changes in bone turnover in women with metabolic syndrome are mediated by changes in PTH.

\section{Discussion}

Weight, abdominal fat mass, BMI and lumbar spine bone mineral content were significantly greater in women whose WC greater than or equal to $88 \mathrm{~cm}$. The lumbar bone density was also higher in these women, but the difference did not achieve statistical significance. There were no significant differences in the biochemical variables or daily dietary calcium intake between the 2 groups of women. Serum 25OHD level was negatively correlated with WC implying that overweight or obese states or metabolic syndrome may be associated with lower vitamin D status.

Following the supplemented milk drink, only ionized Ca changed significantly from baseline. After this drink, the fall in CTX was only significant in women with a WC $\geq 88 \mathrm{~cm}$ and not in those with a $\mathrm{WC}<88 \mathrm{~cm}$.

Dietary calcium when ingested with a meal including a dairy drink, is influenced by other co-ingested nutrients likely to influence bioavailability and metabolism of calcium. The effect of carbohydrate on bone metabolism is marked and acts through the increase in plasma levels of incretin hormones, particularly glucagon-like peptide 2 (GLP-2) [15]. Osteocalcin, a protein produced by the bone forming osteoblasts is considered to provide a link between energy metabolism and bone [16]. The absence of osteocalcin reduces beta cell proliferation and leads to glucose intolerance and insulin resistance. Osteocalcin is thought to sensitize adipocytes to insulin via adiponectin,

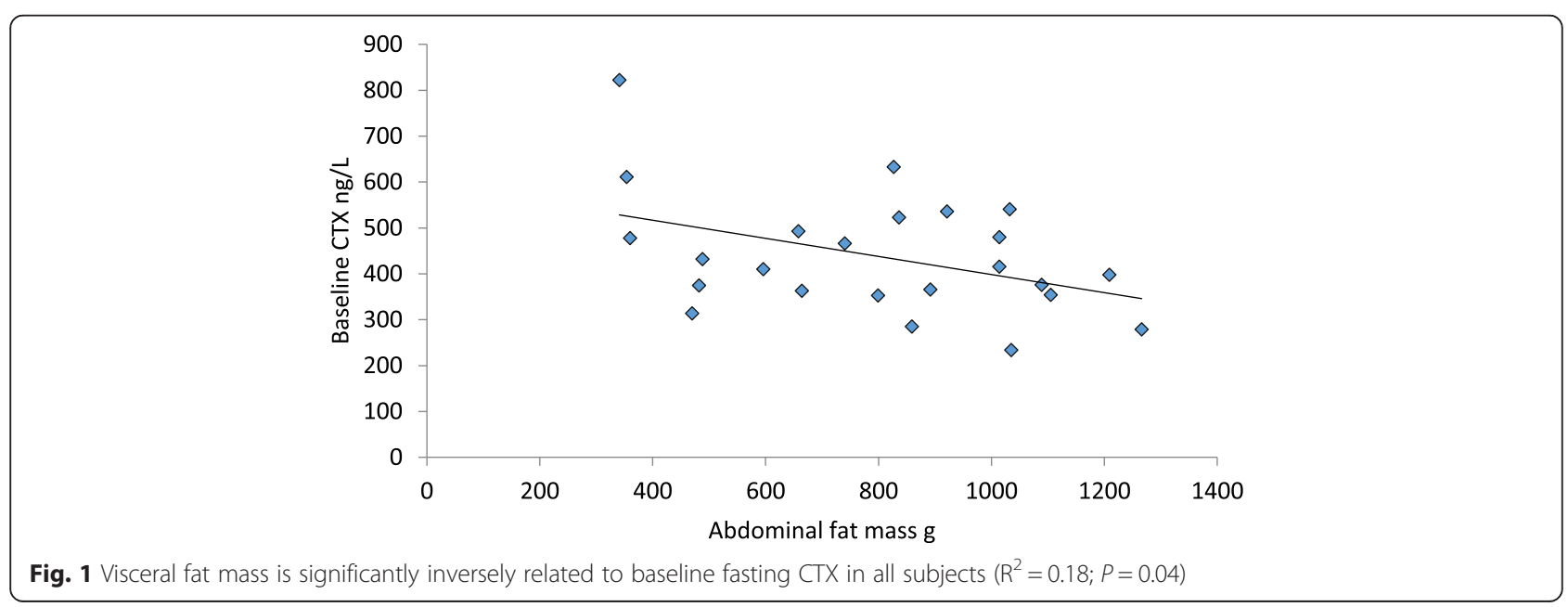


Table 2 Biochemical variables before and after the supplemented milk drink

\begin{tabular}{llll}
\hline Variable & Before drink [mean (SD)] & After drink [mean (SD)] & Level of significance \\
\hline Glucose mmol/L & $4.9(1)$ & $4.8(1)$ & 0.4 \\
Total cholesterol mmol/L & $5.6(1)$ & $5.6(1)$ & 0.4 \\
Total Ca mmol/L & $2.37(0.08)$ & $2.4(0.09)$ & 0.12 \\
lonised Ca mmol/L & $1.21(0.04)$ & $1.23(0.04)$ & $0.05^{*}$ \\
Phosphate mmol/L & $1.18(0.13)$ & $1.22(0.13)$ & 0.15 \\
ALP IU/L & $75(19)$ & $71(20)$ & 0.24 \\
CTX ng/L & $432(132)$ & $416(143)$ & 0.3 \\
PTH pmol/L & $4.3(1.1)$ & $4(1)$ & 0.13 \\
$25 \mathrm{OHD} \mathrm{nmol/L}$ & $88(26)$ & $\mathrm{NA}$ & $\mathrm{NA}$ \\
\hline
\end{tabular}

${ }^{*} P=0.05$

thereby improving glucose tolerance. These findings suggest that bone turnover is intimately associated with carbohydrate metabolism and insulin sensitivity or resistance.

In addition protein plays a major role in calcium homeostasis, presumably via IGF-1 [17]. Indeed, medium term studies on dietary calcium intakes show a rise in IGF-1 due to protein in cheese with a concurrent fall in bone turnover markers. Very low protein diets result in hypocalciuria, low fractional calcium absorption and secondary hyperparathyroidism while a high protein diet enhances fractional calcium absorption and consequent urinary calcium excretion [18].

Nutrient intake and caloric intake, among other factors, plays a major role in the development of metabolic syndrome. Metabolic syndrome, due to derangement in various metabolic processes such as insulin resistance, may influence the handling of ingested nutrients.
Obesity may protect mammals from osteoporosis, and bone metabolism may indeed be linked to energy metabolism. This link may be the hormones exerting their effects on both bone and energy metabolism under the influence of the hypothalamus [19]. This concept of a gut-brain-bone axis has led to investigations on the effects of nutrients on enteroendocrine cells, and the effect of their secretions (incretins or gut derived hormones) on bone and other tissue. The proposed link between incretins and bone is an evolving concept in nutrient-dependent regulation of bone turnover. The postprandial fall in bone resorption markers and the rise in bone formation markers (albeit to a lesser extent) has been attributed to the effects of incretins GLP-1 mainly, with GLP-2 playing a minor role [20, 21].

The adipocyte derived hormone, leptin is a major regulator of osteoblast function, and inhibit bone

Table 3 Anthropometric and biochemical measuresfor the 2 groups of subjects

\begin{tabular}{llll}
\hline Anthropometric measurement & $\begin{array}{l}\text { Subjects with waist circumference }<88 \mathrm{~cm} ; \\
\text { mean }(\mathrm{SD}) \mathrm{N}=16\end{array}$ & $\begin{array}{l}\text { Subjects with waist circumference } \geq 88 \mathrm{~cm} ; \\
\text { mean (SD) } N=8\end{array}$ \\
\hline Lumbar spine BMD g/cm2 & $1.039(0.212)$ & $1.167(0.115)$ & $P$ \\
Lumbar spine BMC g & $45.35(9.95)$ & $55.46(8.75)$ & 0.06 \\
Lean mass g & $1567(190)$ & $1540(253)$ & $0.011^{*}$ \\
Fat mass g & $655(222)$ & $1071(132)$ & 0.38 \\
Height $\mathrm{m}$ & $1.63(0.05)$ & $1.63(0.04)$ & $0.000^{* *}$ \\
Weight $\mathrm{kg}$ & $62.5(8.9)$ & $73(5.6)$ & 0.47 \\
Waist circumference cm & $79(7)$ & $94(3)$ & $0.003^{*}$ \\
BMl kg/m2 & $23.57(2.52)$ & $27.59(2.38)$ & $0.000^{* *}$ \\
Fasting glucose $\mathrm{mmol} / \mathrm{L}$ & $4.650 .49)$ & $5.34(1.8)$ & $0.000^{* *}$ \\
Total cholesterol mmol/L & $5.48(0.8)$ & $5.98(0.8)$ & 0.08 \\
Triglycerides mmol/L & $0.99(0.37)$ & $1.24(0.43)$ & 0.13 \\
HDL mmol/L & $1.74(0.37)$ & $1.6(0.14)$ & 0.11 \\
LDL mmol/L & $3.23(0.69)$ & $3.6(1.23)$ & 0.21 \\
\hline
\end{tabular}


Table 4 Changes in biochemical variables after the supplemented milk drink in the 2 groups of subjects

\begin{tabular}{lll}
\hline Variable & $\begin{array}{l}\text { Change after the supplemented milk drink in women } \\
\text { with WC }<88 \mathrm{~cm} \text {; mean (SD) }\end{array}$ & $\begin{array}{l}\text { Change after the supplemented milk drink in women } \\
\text { with WC }=/>88 \mathrm{~cm} \text { mean (SD) }\end{array}$ \\
\hline Glucose $\mathrm{mmol} / \mathrm{L}$ & $-0.11(0.5)$ & $-0.1(0.36)$ \\
Total cholesterol mmol/L & $-0.05(0.33)$ & $0.09(0.19)$ \\
PO4 mmol/L & $0.03(0.12)$ & $0.06(0.04)$ \\
Total Ca mmol/L & $0.03(0.07)$ & $0.02(0.04)$ \\
lonised Ca mmol/L & $0.02(0.04)$ & $0.02(0.03)$ \\
ALP IU/L & $-0.9(5.7)$ & $-10.6(24.3)$ \\
CTX ng/L & $-0.33(37.46)$ & $-53(45.2)$ \\
PTH pmol/L & $-0.4(0.65)$ & $-0.57(0.66)$ \\
\hline
\end{tabular}

$* P<0.005$

formation in vivo [22, 23]. Leptin deficient or leptin receptor deficient mice display an osteopetrotic skeletal phenotype at an early age with high trabecular bone volume [24], however there was a demonstrable decline in the rate of bone formation (BFR) and resorption (BRR). Interestingly, peripheral administration of leptin corrected BFR and BRR demonstrating that leptin was directly involved in regulating bone turnover. In contrast, in humans, low circulating leptin was associated with low bone density [25].

As in any other endocrine pathway, it can be postulated that adipocytes and leptin production in turn, may be under a feedback regulatory control of bone metabolism. Osteocalcin, an osteoblast specific protein, seems a suitable candidate. Indeed, glucose intolerance and greater amounts of visceral fat were noted in Osteocalcin knockout mice (Osteocalcin ${ }^{-1-}$ ) [16]. Furthermore, deletion of other genes in osteoblasts in mice led to pancreatic $\beta$ cell proliferation, a rise in insulin secretion and sensitivity that protected against obesity and diabetes, demonstrating at least the capacity of osteoblasts to contribute to energy metabolism. It follows then that deranged energy metabolism, as in the metabolic syndrome with glucose intolerance and greater visceral fat, may influence bone metabolism. We hypothesis that responses of bone metabolism to dietary calcium may differ between women with and without metabolic syndrome.

\section{Conclusions}

Given that there were no differences in calcium absorption or the rate of urinary calcium excretion between the 2 groups of women, the findings reported here suggest that metabolic syndrome may have influenced the fall of CTX in response to dietary Ca. There was a trend for baseline CTX to be lower in women with higher visceral fat. These findings are consistent with previous proposed theories of obesity protecting against osteoporosis presumably via leptin and hypothalamic feedback, closely associated with energy metabolism [19]. Our data also imply that bone turnover in overweight women or women with metabolic syndrome was more sensitive to dietary calcium intake.

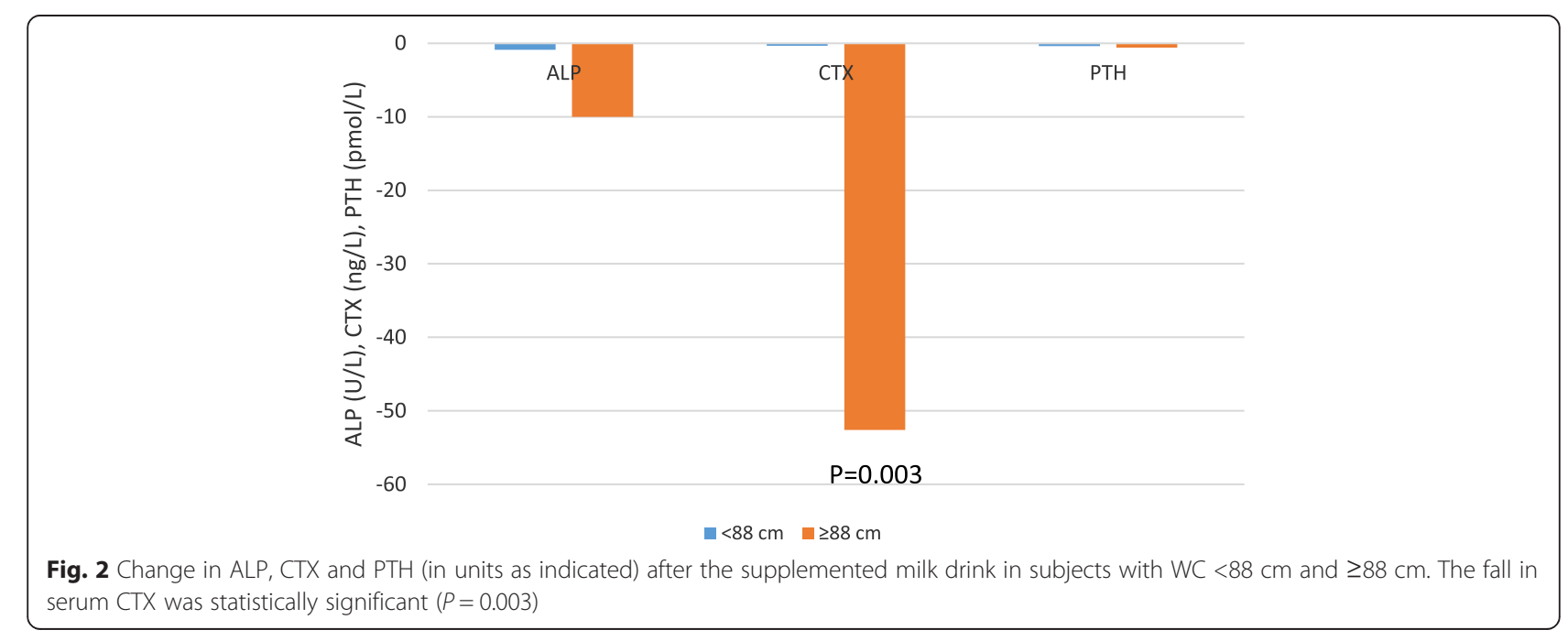




\section{Competing interests}

The authors declare that they have no competing interests.

\section{Authors' contributions}

BECN designed the experiment, SDCT conducted the experiment, analysed the data and drafted the manuscript, HAM helped analyse the data and contributed to the manuscript. SDCT and HAM read and approved the final manuscript.

\section{Sources of Funding}

This study was funded by a Royal Adelaide Hospital Research Grant.

\section{Author details}

${ }^{1}$ Department of Medicine, University of Adelaide, Adelaide, South Australia, Australia. ${ }^{2}$ Endocrine and Metabolic Unit, Royal Adelaide Hospital, Level 7, Royal Adelaide Hospital, North Terrace, Adelaide, South Australia 5000, Australia. ${ }^{3}$ School of Pharmacy and Health Sciences, University of South Australia, Adelaide, South Australia, Australia. ${ }^{4}$ Chemical Pathology, SA Pathology, Adelaide, South Australia, Australia.

Received: 20 May 2015 Accepted: 21 September 2015

Published online: 25 September 2015

\section{References}

1. Bischoff-Ferrari HA, Staehelin HB. Importance of vitamin D and calcium at older age. Int J Vitam Nutr Res. 2008;78:286-92.

2. Rizzoli R, Bianchi ML, Garabedian M, McKay HA, Moreno LA. Maximizing bone mineral mass gain during growth for the prevention of fractures in the adolescents and elderly. Bone. 2010;46:294-305.

3. Heaney RP. Calcium needs of the elderly to reduce fracture risk. J Am Coll Nutr. 2001;20:192S-7S.

4. Nordin BEC. Calcium requirement is a sliding scale. Am J Clin Nutr. 2000;71:1381-3.

5. Weaver CM, Proulx WR, Heaney R. Choices for achieving adequate dietary calcium with a vegetarian diet. J A Coll Nutr. 1999;70:543S-8S.

6. Bonjour JP, Benoit V, Pourchaire O, Ferry M, Rousseau B, Souberbielle JC. Inhibition of markers of bone resorption by consumption of vitamin $\mathrm{D}$ and calcium-fortified soft plain cheese by institutionalised elderly women. B J Nutr. 2009;102:962-6.

7. Bonjour JP, Benoit V, Rousseau B, Souberbielle JC. Consumption of vitamin $\mathrm{D}$ and calcium fortified soft white cheese lowers the biochemical marker of bone resorption TRAP 5b in postmenopausal women at moderate risk of osteoporosis fracture. J Nutr. 2012;142:698-703.

8. Bonjour J-P, Benoit V, Payen F, Kraenzlin M. Consumption of yogurts fortified in vitamin $D$ and calcium reduces serum parathyroid hormone and markers of bone resorption: A double-blind randomized controlled trial in institutionalized elderly women. J Clin Endocr Metab. 2013;98:2915-21.

9. Boonan S, Lips P, Bouillon R, Bischoff-Ferrari HA, Vanderschueren D, Haentjens $P$. Need for additional calcium to reduce the risk of hip fracture with vitamin D supplementation: Evidence from a comparative metaanalysis of randomized controlled trials. J Clin Endocr Metab. 2007;92:1415-23.

10. Warensjo E, Byberg L, Melhus H, Gedeborg R, Mallmin H, Wolk A, et al. Dietary calcium intake and risk of fracture and osteoporosis: longitudinal cohort study. Brit Med J. 2011;42:1473.

11. Nordin BEC, Morris HA, Wishart JM, Scopacasa F, Horowitz M, Need AG, et al. Modification and validation of a single-isotope radiocalcium absorption test. J Nucl Med. 1998;39:108-13.

12. Expert Panel on Detection, Evaluation, and Treatment of High Blood Cholesterol in Adults. Executive summary of the third report of the National Cholesterol Education Program (NCEP) Expert Panel on Detection, Evaluation, and Treatment of High Blood Cholesterol in Adults (Adult Treatment Panel III). JAMA. 2001;285:2486-97.

13. www.heartfoundation.org.au/healthy-eating/Pages/waist-measurement.aspx accessed 01/08/2015.

14. Alberti KG, Eckel RH, Grundy JM, Zimmet PZ, Cleeman JI, Donato KA, et al. Harmonizing the metabolic syndrome: a joint interim statement of the International Diabetes Federation Task Force on Epidemiology and Prevention; National Heart, Lung, and Blood Institute; American Heart Association; World Heart Federation; International Atherosclerosis Society; and International Association for the Study of Obesity. Circulation. 2009;120(16):1640-5.
15. Henriksen DB, Alexandersen P, Bjarnason NH, Vilsboll T, Harmann B, Henriksen $\mathrm{EE}$, et al. Role of gastrointestinal hormones in postprandial reduction of bone resorption. J Bone Miner Res. 2003;18:2180-9.

16. Lee NK, Sowa H, Hinoi E, Ferron M, Ahn JD, Confavreux C, et al. Endocrine regulation of energy metabolism by the skeleton. Cell. 2007;130:456-69.

17. Dubois-Ferrier V, Brennan TC, Dayer R, Rizzoli R, Ammann P. Calcitropic hormones and IGF-1 are influenced by dietary protein. Endocrinology. 2011;152(5):1839-47.

18. Kerstetter JE, O'Brien KO, Insogna KL. Dietary protein, calcium metabolism and skeletal homeostasis revisited. Am J Clin Nutr. 2003;78(suppl):584S-92S.

19. Ducy P, Amling M, Takeda S, Priemel M, Schilling AF, Beil FT, et al. Leptin inhibits bone formation through a hypothalamic relay: a central control of bone mass. Cell. 2000;100:197-207.

20. Henriksen DB, Alexandersen P, Bjarnason NH, Vilsboll T, Harmann B, Henriksen $\mathrm{EE}$, et al. Role of gastrointestinal hormones in postprandial reduction of bone resorption. J Bone Miner Res. 2003;18:2180-9.

21. Clowes JA, Hannon RA, Yap TS, Hoyle NR, Blumsohn A, Eastell R. Effects of feeding on bone turnover markers and its impact on biological variability of measurements. Bone. 2002;30:886-90.

22. Karsenty G. Convergence between bone and energy homeostasis: Leptin regulation of bone mass. Cell Metab. 2006:4:341-8.

23. Elefteriou F, Takeda S, Ebihara K, Magre J, Patano N, Kim CA, et al. Serum leptin level is a regulator of bone mass. P Natl Acad Sci USA. 2004;101:3258-63.

24. Turner RT, Kalra SP, Wong CP, Philbrick KA, Lindenmaier LB, Boghossian S, et al. Peripheral leptin regulates bone formation. J Bone Miner Res. 2013;28:22-34.

25. Legroux-Gerot I, Vignau J, Biver E, Pigny P, Collier F, Marchandise X, et al. Anorexia nervosa, osteoporosis and circulating leptin: the missing link. Osteoporosis Int. 2010;21:1715-22.

\section{Submit your next manuscript to BioMed Central and take full advantage of:}

- Convenient online submission

- Thorough peer review

- No space constraints or color figure charges

- Immediate publication on acceptance

- Inclusion in PubMed, CAS, Scopus and Google Scholar

- Research which is freely available for redistribution 